\title{
Quantitative measurement of iron stores with diethylenetriamine penta-acetic acid
}

\author{
MICHAEL BARRY, GUISEPPE CARTEI, AND SHEILA SHERLOCK \\ From the Department of Medicine, The Royal Free Hospital, London
}

SUMMARY The use of the chelating agent diethylenetriamine penta-acetic acid (DTPA) for measuring body storage iron was investigated in patients with iron excess whose stores could be determined by venesection.

Iron excretion after DTPA bore a close semi-logarithmic relationship to body iron stores when these were increased. The excretion of DTPA-bound ${ }^{59} \mathrm{Fe}$ was similarly related to the size of the stores, indicating that the increased iron excretion produced by DTPA in iron overload states reflects both increased tissue iron available for chelation and greater stability of the iron-chelate complex. Evidence was obtained that injected ${ }^{59} \mathrm{Fe}-\mathrm{DTPA}$ could be used as a marker for chelated tissue iron enabling the DTPA-chelatable body iron pool to be calculated.

There was a highly significant correlation between DTPA-chelatable iron and body storage iron. The regression intercept approximated to the origin, implying a specific relation between the DTPA effect and storage iron. The SE of the mean estimate for storage iron on DTPAchelatable iron was $0.25 \mathrm{~g}(5 \cdot 6 \%)$.

Mean storage iron values of $392 \mathrm{mg}$ for males and $243 \mathrm{mg}$ for females were predicted from the findings in control subjects.

Recent studies have shown that desferrioxamine may be used to give a quantitative estimate of body storage iron in patients with idiopathic haemochromatosis (Balcerzak, Westerman, Heinle and Taylor, 1968; Barry, Cartei, and Sherlock, 1969; Smith, Lestas, Miller, Dymock, Pitcher, and Williams). However, there is evidence that this chelating agent also derives iron from tissue sources unrelated to the stores and that its action may not always closely reflect the content of body storage iron (Fielding, 1965; Hallberg, Hedenberg, and Weinfeld, 1966; Balcerzak et al, 1968; Lundvall and Weinfeld, 1969; Barry et al, 1969). Having found that the effect of desferrioxamine correlated poorly with the size of the stores in liver diseases other than haemochromatosis (Barry et al, 1969) we investigated the synthetic chelating agent diethylenetriamine penta-acetic acid.

Received for publication 23 June 1970.
Diethylenetriamine penta-acetic acid is particularly suitable for diagnostic purposes as it is completely and rapidly eliminated in the urine in unchanged form (Stevens, Rosoff, Weiner, and Spencer, 1962). Clinical studies have suggested that iron excretion after DTPA closely reflects the size of the stores (Walsh, Perkins, Blackburn, Sanford, and Cantrill, 1963; Powell and Thomas, 1967). However, there is evidence that the ironDTPA complex dissociates to a considerable and variable extent in vivo (Cleton, Turnbull, and Finch, 1963); as only the iron of the undissociated complex can be excreted, it follows that the iron present in the urine may not be a constant sample of the quantity chelated in the tissues.

The present study was designed to examine the interrelationships between (1) the endogenous iron excretion produced by DTPA, (2) the stability of the iron-DTPA complex in vivo, as indicated by the percentage of an injected quantity 
of ${ }^{59} \mathrm{Fe}-\mathrm{DTPA}$ excreted in the urine, and (3) body-storage iron content in a group of patients with iron excess whose stores could be measured by venesection. The excretion, of endogenous iron and of injected ${ }^{59} \mathrm{Fe}-\mathrm{DTPA}$ were found to vary in equal proportion with each other at different stages of treatment, indicating that the labelled material could be used as a marker for chelated tissue iron. This enabled the total quantity of iron chelated in the tissues (DTPA-chelatable body iron) to be calculated in a manner analogous to the differential ferrioxamine test (Fielding, 1965 and 1967; Barry et al, 1.969; Smith et al, 1969).

\section{Materials and Methods}

\section{MATERIALS}

DTPA was supplied as a sterile $25 \%$ solution of trisodium calcium DTPA, $1 \mathrm{~g}$ per $4 \mathrm{ml}$ ampoule (Geigy Pharmaceuticals, Macclesfield, Cheshire). This substance (mol weight 497) binds ferric iron strongly over the $p \mathrm{H}$ range 4-8, one iron atom per molecule of chelating agent. The stability constant of the ferric chelate is $\mathbf{1 0}^{27}$ (Schubert, 1964).

A sterile stock solution of ${ }^{59} \mathrm{FeCl}_{3}$, of specific activity 5-10 $\mu \mathrm{Ci} / \mu \mathrm{g}$ (The Radiochemical Centre, Amersham), was diluted with distilled water to give a ${ }^{59} \mathrm{Fe}$ solution $2 \mu \mathrm{Ci} / \mathrm{ml}$. One volume of this solution was mixed with 4 volumes of $25 \%$ DTPA to give a solution of DTPA, $200 \mathrm{mg} / \mathrm{ml}$, containing a trace quantity of ${ }^{59} \mathrm{Fe}-\mathrm{DTPA}$.

\section{CLINICAL PROCEDURE}

DTPA was administered in a dose of approximately $16.7 \mathrm{mg} / \mathrm{kg}$ body weight; the volume of labelled solution (ml) containing this dose, taken to the nearest $0.5 \mathrm{ml}$, was calculated for each subject from the formula $16 \cdot 7 / 200 \times$ body weight $(\mathrm{kg})$. The subject voided urine immediately before the test. The dose-volume of labelled DTPA solution, accurately drawn up to the appropriate calibration mark in a glass syringe, was injected intravenously over one to two minutes. The syringe and needle set was retained for accurate calibration. A six-hour urine collection was made into a wide-mouthed, iron-free polyethylene bottle. Iron-free polypropylene bedpans were used as intermediate receptacles for patients unable to void directly into the bottle.

\section{ANALYTICAL PROCEDURE}

After rinsing, the syringe and needle set was filled with distilled water exactly to the calibration mark used for the injection and the weight of the discharged contents determined, reproducing the injected volume to within $\pm 0.01 \mathrm{ml}$. An aliquot of the labelled solution, reserved for the purpose, was diluted 1 in 100 with water and the ${ }^{59} \mathrm{Fe}$ activity in $5 \mathrm{ml}$ determined in an automatic gamma spectrometer (Packard) using a counting time of 1,000 seconds. The ${ }^{59} \mathrm{Fe}$ activity in an undiluted $5 \mathrm{ml}$ aliquot of urine was determined at the same time. After subtracting background activity and correcting for dilution the activities were expressed as cts $/ \mathrm{ml} / 100 \mathrm{sec}$. The total activity excreted could then be expressed as a percentage of that injected. Urinary iron concentration was determined colorimetrically with bathophenanthroline sulphonate after wet ashing (Barry, 1968).

Serum iron and total iron-binding capacity were determined by an AutoAnalyzer (Young and Hicks, 1965). The stainable iron content of liver biopsy specimens was assessed by the method of Scheuer, Williams, and Muir (1962).

\section{CALCULATIONS}

The total iron excreted in the six-hour urine was calculated. The ${ }^{59} \mathrm{Fe}$ activity excreted was expressed as a percentage of the activity injected. DTPA-chelatable body iron was calculated by simple proportion.

DTPA-chelatable iron $(\mathrm{mg})=$

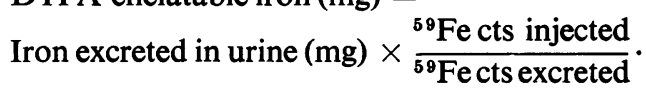

\section{Subjects Studied}

CONTROL SUBJECTS

Four healthy volunteers and 21 informed medical ward patients agreed to act as controls. The mean age in the 16 males was $47 \pm 4 \mathrm{yr}$ and in the nine females $48 \pm 3$ yr. Each subject had a normal haemoglobin concentration, serum iron level, and total iron-binding capacity; the mean values for the group are summarized in Table I. The clinical record of the patients indicated that unphysiological blood loss, disordered iron metabolism, or dyserythropoiesis were unlikely to be present.

PATIENTS WITH IRON OVERLOAD

Twelve patients with idiopathic haemochromatosis (including two mildly affected siblings of cases), one patient with haemochromatosis secondary to hereditary spherocytosis, and two patients with cirrhosis and siderosis were studied prospectively in relation to multiple venesection therapy (Table II). Treatment was already well advanced in several cases at the time of first study and in one it has not yet been completed. Fourteen patients were venesected to complete iron store depletion, enabling the mobilizable iron stores before the start of treatment, or at any time during its course, to be calculated from the quantity of haemoglobin iron subsequently removed. The methods relating to the venesection 


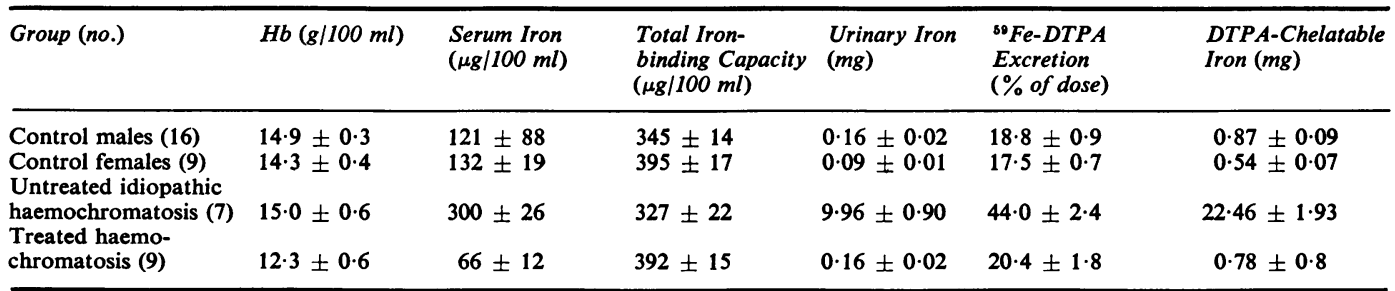

Table I Mean $( \pm S E M)$ values for control subjects and patients with untreated and completely treated haemochromatosis

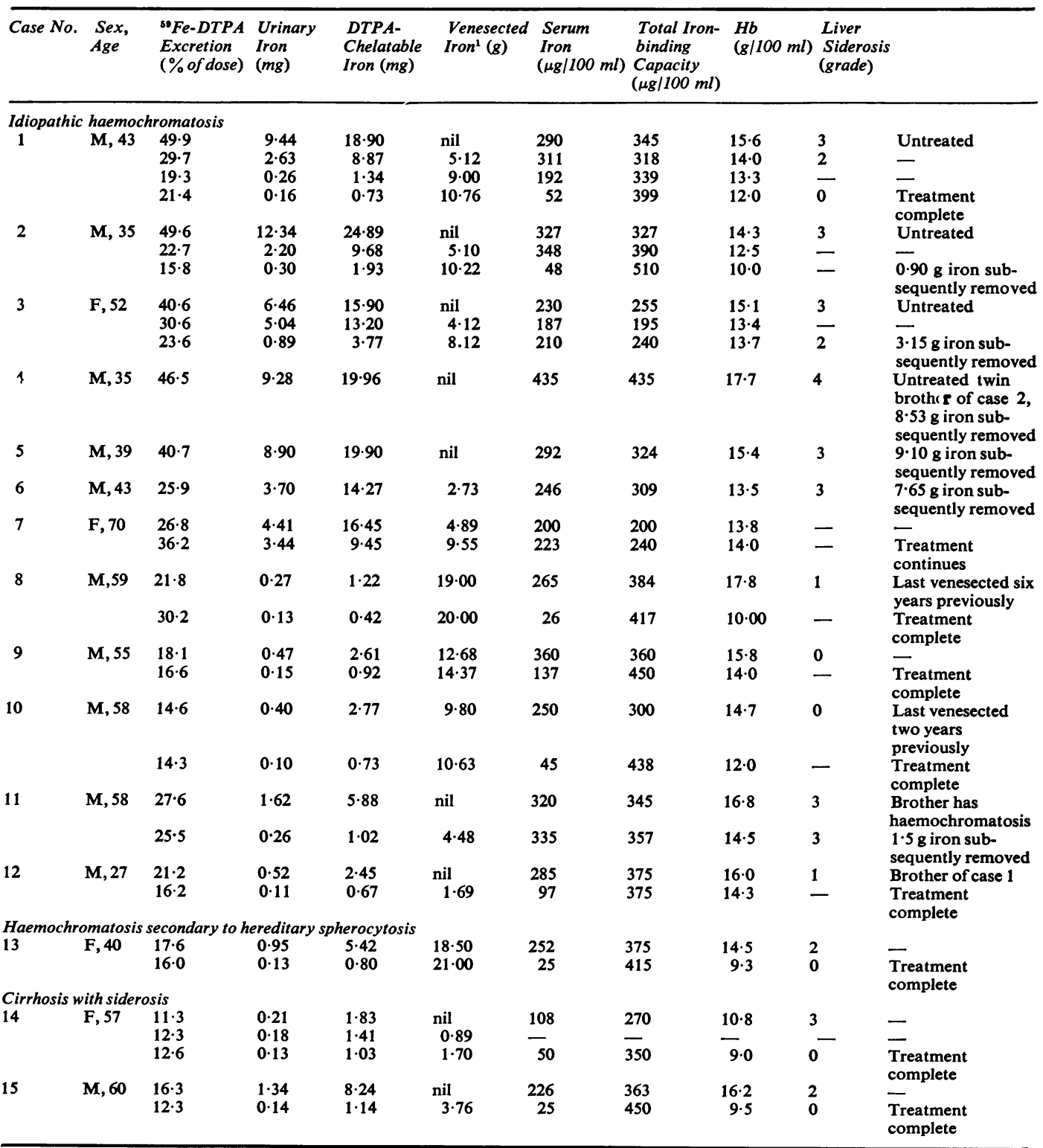

Table II Details of patients with iron overload studied at different stages during treatment by repeated venesection

${ }^{1}$ Cumulative total of haemoglobin-iron removed up to the time of each DTPA study. 
procedure and to the calculation of mobilizable storage iron have been previously described (Barry et al, 1969).

\section{Results}

EXCRETION OF INJECTED ${ }^{5}$ FE-DTPA The percentage of an intravenous trace dose of ${ }^{59} \mathrm{Fe}-\mathrm{DTPA}$ excreted by control subjects and patients with untreated and completely idiopathic haemochromatosis is shown in Fig. 1; the findings in certain other groups are included for comparison. A six-hour urine collection was made after observations in five subjects had shown that the mean $\left( \pm\right.$ SEM) ${ }^{59} \mathrm{Fe}$ activity excreted in this time was $97.6 \pm 0.9 \%$ of the total activity excreted in 24 hours. Control subjects, patients with chronic cholestasis, and most patients with cirrhosis excreted $12-28 \%$ of the injected label. A greater fraction was excreted by certain patients with cirrhosis, particularly those with a portacaval anastomosis, and by 12 out of 14 patients with untreated haemochromatosis. Excretion was low in six patients with known renal dysfunction, the mean $( \pm$ SEM) value being $6.6 \pm 0.6 \%$; these results have been omitted from Figure 1. Eight of the lower values in the cirrhosis group and the two lowest in the group with secondary haemochromatosis were in patients with ascites; in one of the latter the ${ }^{59} \mathrm{Fe}$-DTPA excretion before, and 10 days after, effective diuretic $\Omega$ therapy was $25.3 \%$ and $37.5 \%$ respectively, compared with a maximum difference of $2.7 \% \stackrel{\overrightarrow{\mathrm{S}}}{\overrightarrow{\mathrm{S}}}$ between repeat tests in five steady state subjects. $\frac{\vec{\sigma}}{0}$

Increased excretion of ${ }^{59} \mathrm{Fe}-\mathrm{DTPA}$ was only seen in patients with a high serum iron or a low $\overline{\bar{c}}$ unsaturated iron-binding capacity, although not $\vec{\nabla}$ all such subjects had increased excretion of the $\propto$ chelate. In the patients with iron overload there कै was a highly significant semi-logarithmic relation- $\overrightarrow{0}$ ship between the quantity of label excreted at different stages of treatment and the size of the iron stores (Fig. 2).

ENDOGENOUS IRON EXCRETION PRODUCED BY DTPA IN CONTROL SUBJECTS AND IN PATIENTS WITH HAEMOCHROMATOSIS The findings are summarized in Table $\mathrm{I}$. In the controls iron excretion exceeded $\mathbf{0 . 2 4} \mathrm{mg}$ in only $\rightarrow$ one case. The difference between the sexes was $z$ significant $(t=2 \cdot 60, P<0.02)$. In propositi with untreated idiopathic haemochromatosis iron $\exists$ excretion ranged from $6.46 \mathrm{mg}$ to $13.74 \mathrm{mg}$. In $\mathbb{\Phi}$ nine cases of haemochromatosis studied less than three months after the completion of treatment the mean excretion was lower than in control males but the difference was not significant.

Extrapolation of the regression line relating cumulative iron excretion by a normal subject to

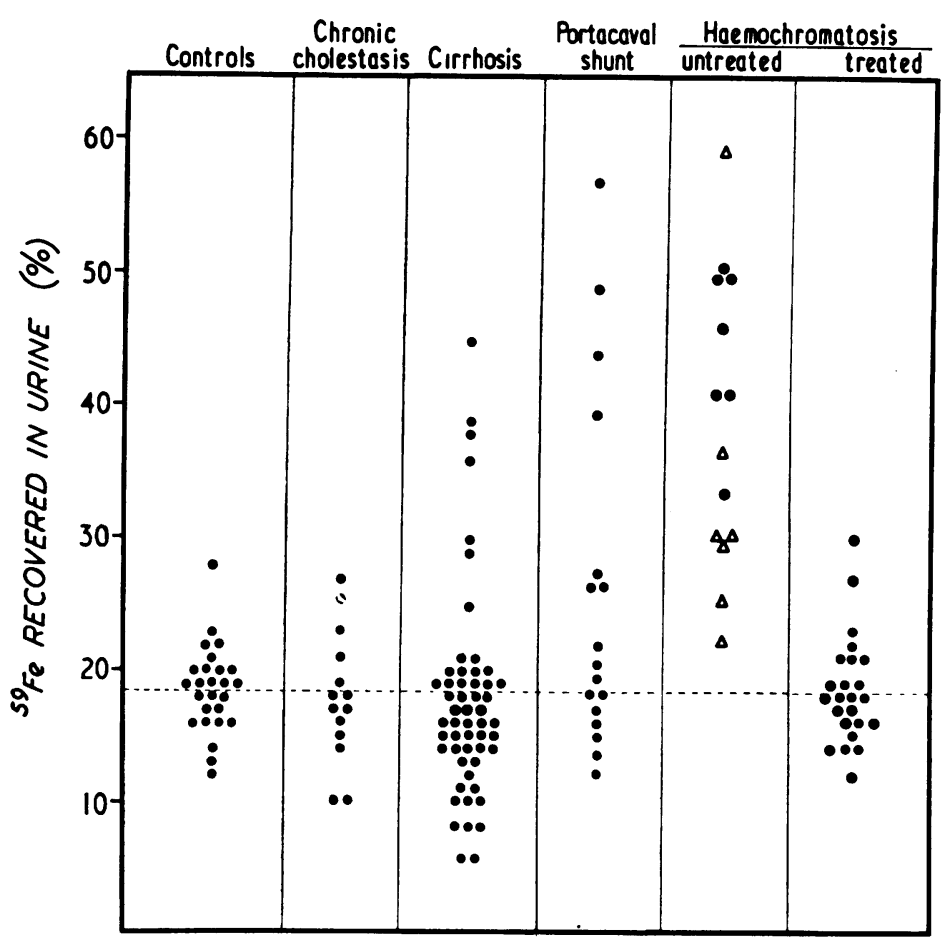

Fig. 1

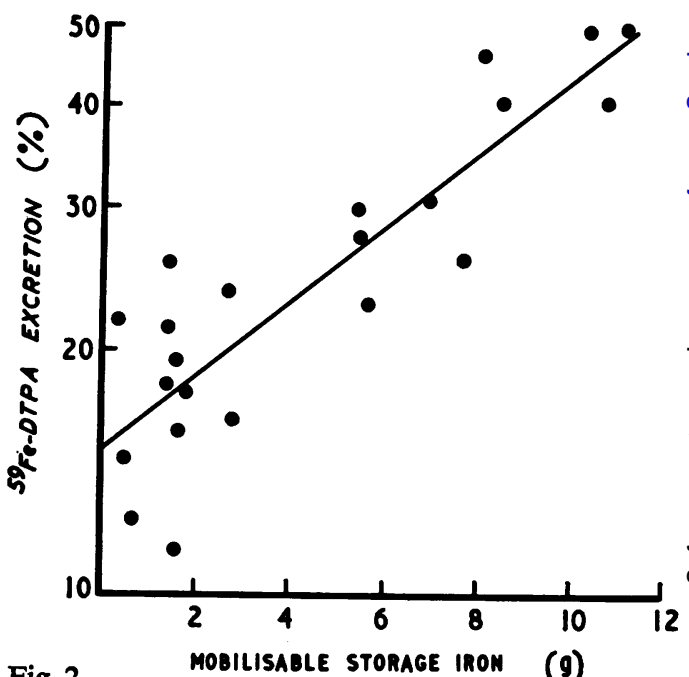

Fig. 2

Fig. 1 The percentage of an intravenous trace dose of DTPA-bound ${ }^{59} \mathrm{Fe}$ excreted in the urine by control subjects and patients with chronic liver disease. The horizontal broken line indicates the mean value for controls $(18.4 \%) . \Delta=$ secondary haemochromatosis.

Fig. 2 Relation between ${ }^{59} \mathrm{Fe}-\mathrm{DTPA}$ excretion and mobilizable storage iron in patients with iron overload treated by venesection $(r=0.88, \mathrm{P}<0.001)$. 


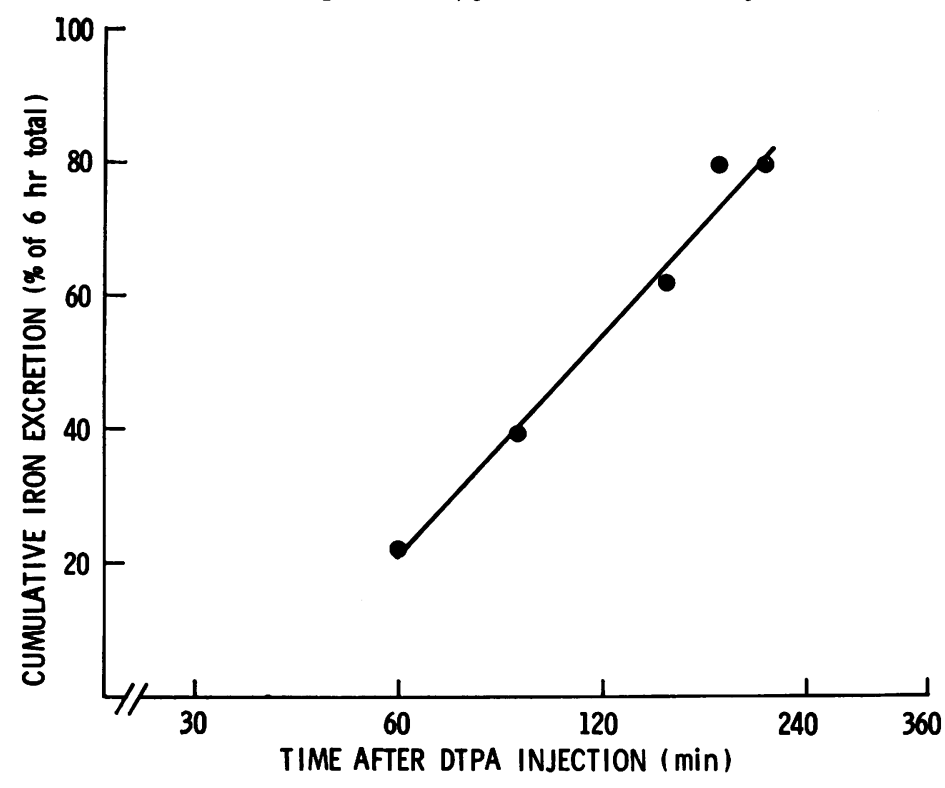

Fig. 3 Relation between cumulative iron excretion (expressed as percentage of the total iron excreted in six hours) and time after DTPA administration in a normal subject. Each plot represents a separate study. Correction was made for physiological iron excretion $(y=110.3 \log x-175, r=0.99)$.



Fig. 4 Relation between iron excretion produced by DTPA and mobilizable storage iron $(\log y(\mu g)=$ $2 \cdot 3851+0 \cdot 163 x)$. six hours had appeared in the urine at one hour, and $99.2 \%$ at three hours. Thus the excretion of injected preformed chelate was more rapid than that of iron bound in vivo, the difference implying that the process of tissue iron chelation is slow compared with that of chelate excretion.

INTERRELATIONSHIPS BETWEEN THE IRON STORES, ENDOGENOUS IRON EXCRETION, AND ${ }^{59}$ FE-DTPA EXCRETION

The endogenous iron excretion produced by DTPA, like that of injected ${ }^{59} \mathrm{Fe}-\mathrm{DTPA}$, was semi-logarithmically related to the size of the iron stores (Fig. 4), the SE of the mean estimate for storage iron on iron excretion being $0.25 \mathrm{~g}$. Scrutiny of Fig. 6 suggests that in fact the log relationship did not apply to low iron loads, and in keeping with this the value of the calculated intercept exceeded the iron excretion observed in treated cases and in controls (Table I).

There was a highly significant correlation between the fall in endogenous iron excretion and the fall in ${ }^{59} \mathrm{Fe}-\mathrm{DTPA}$ excretion as iron load decreased during treatment (Fig. 5), the regression slope indicating that for a change in one there was a proportionally identical change in

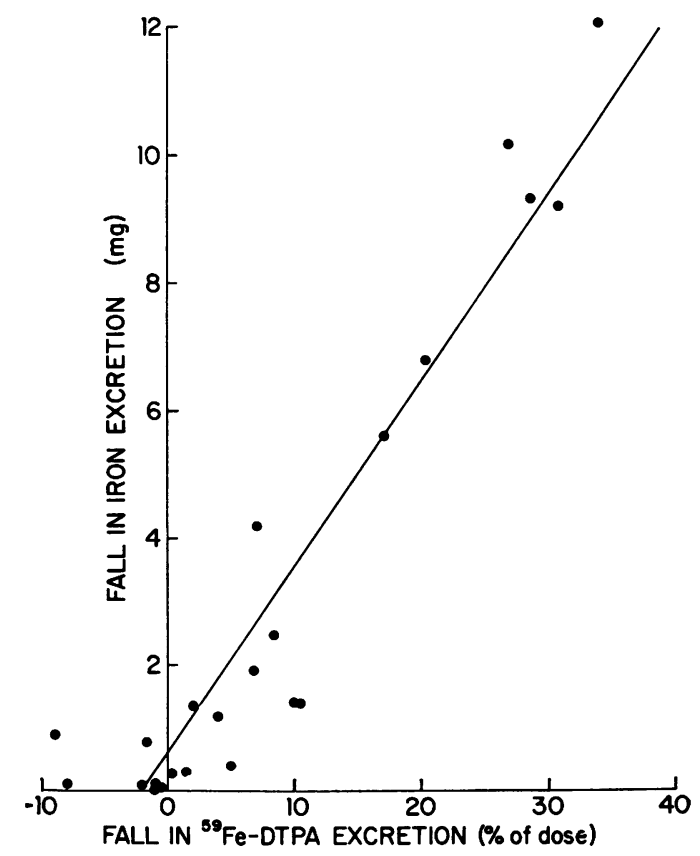

Fig. 5 Relation between the fall in endogenous iron excretion after DTPA and the fall in injected ${ }^{59} \mathrm{Fe}-$ DTPA excretion during treatment in patients with iron overload $(y=0.62+0.29 x, r=0.94)$. The regression slope indicates that a change in one variable was accompanied by a proportionally identical change in the other. 
the other. It follows that injected ${ }^{59} \mathrm{Fe}-\mathrm{DTPA}$ may be used to indicate the fraction of chelated tissue iron excreted in the urine, enabling the total quantity bound in vivo to be calculated.

DTPA-CHELATABLE IRON IN CONTROL SUBJECTS AND PATIENTS WITH HAEMOCHROMATOSIS

The results are summarized in Table I. The highest value for DTPA-chelatable iron in the controls was $1.59 \mathrm{mg}$; the difference between the sexes was significant $(t=2.50, P<0.02)$. In propositi with untreated idiopathic haemochromatosis the range was $15 \cdot 90-29 \cdot 20 \mathrm{mg}$. The values in patients who had recently completed treatment were not significantly different from those in control males.

RELATION BETWEEN DTPA-CHELATABLE IRON AND BODY STORAGE IRON

There was a highly significant linear relationship between DTPA-chelatable iron and mobilizable storage iron (Fig. 6). The close approximation of the regression line to the origin indicated that the effect of DTPA exclusively reflected storage iron, and this was supported by the finding of an almost identical relationship between the fall in DTPA-chelatable iron between two tests during treatment and the iron mobilized in the intervening period $(y=2 \cdot 00 x-0 \cdot 75)$. The regression line shown in Fig. 6 was recalculated with the roles of the variables reversed, giving the equation $y=0.46 x+0.58$; the slope of this line represented the best estimate for storage iron on DTPAchelatable iron, the SE of the mean estimate being $0.25 \mathrm{~g}(5 \cdot 6 \%)$.

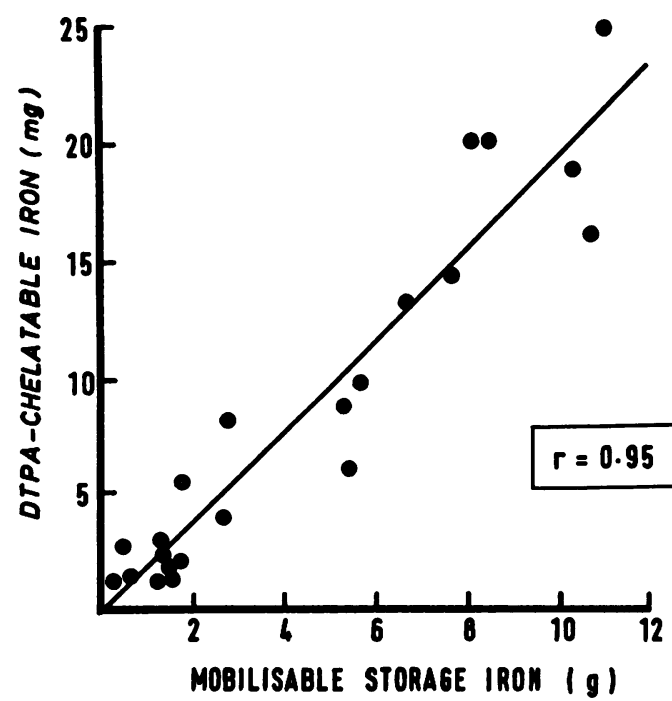

Fig. 6 Relation between DTPA-chelatable iron and mobilizable storage iron $(y=1.97 x-0.30)$.

\section{Discussion}

The metabolism of the synthetic chelating agents? $\left[{ }^{14} \mathrm{C}\right]-E D T A$ and $\left[{ }^{14} \mathrm{C}\right]-D T P A$ has been shown $\overrightarrow{\bar{F}}$ to be similar in several mammalian species, $\stackrel{?}{+}$ including man (Foreman, Vier, and Magee, 1953; 들 Foreman and Trujillo, 1954; Foreman, 1960; $\frac{\bar{c}}{\bar{c}}$ Stevens et al, 1962; Cleton et al, 1963). After $\vec{\sigma}$ intravenous injection these compounds disappear $\propto$ rapidly from the plasma and are distributed in a volume intermediate between the extracellular $\overrightarrow{0}$ space and total body water. There is no evidence of entry into the intracellular compartment but it $\vec{\omega}$ has been suggested they may concentrate on $\stackrel{\Omega}{\varrho}$ cell membranes (Cleton, 1964). Excretion occurs $\subsetneq$

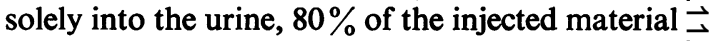
being recovered in unchanged form within six to eight hours, and virtually $100 \%$ within 24 hours of administration; this is in contrast to des- $\stackrel{\oplus}{\oplus}$ ferrioxamine which is both metabolized (Meyer-응 Brunot and Keberle, 1967) and excreted by other routes (Harker, Funk, and Finch, 1968; Figueroa $Z$ and Thompson, 1968).

The fate of intravenously administered ${ }^{59} \mathrm{Fe}-\frac{\Phi}{3}$ labelled chelates was studied by Cleton et al (1963). Immediate plasma clearance was rapid but subsequent disappearance occurred more $\varphi$ slowly than with the $\left[{ }^{14} \mathrm{C}\right]$-labelled chelating. agent, apparently due to recirculation of label transferred from the chelate to transferrin. The excretion of ${ }^{59} \mathrm{Fe}-\mathrm{DTPA}$ in five human subjects $\overline{0}$ varied from 26 to $65 \%$ of the injected label. Our $\stackrel{\circ}{\circ}$ results indicate that only $12-28 \%$ of an intra- $\stackrel{\perp}{\varnothing}$ venous dose of DTPA-bound iron can be elimin- $\overrightarrow{\vec{P}}$ ated by normal human subjects compared with $\frac{3}{3}$ up to $60 \%$ in untreated haemochromatosis. Excretion is closely related to the size of the iron stores, reflecting an effect of the latter on the stability of the iron-chelate complex in vivo. Cleton et al (1963) showed that in the rabbit the $\frac{5}{3}$ retained iron became widely distributed in the tissues, and that in both the rabbit and in man it was partly used for haemoglobin synthesis in a quantitatively similar manner to transferrin iron.

In unpublished observations we have found $\frac{D}{O}$ that an intravenous trace dose of ${ }^{59} \mathrm{Fe}-\mathrm{DTPA}$ is excreted in the same proportion as a large quantity of of simultaneously injected non-radioactive $N$ DTPA-bound iron, indicating that the isotope is $\stackrel{N}{\mathrm{~N}}$ not exchanged for tissue iron. The lack of such $\mathrm{\omega}$ exchange may depend on the rapid rate of chelate excretion compared with the slower process of $\stackrel{\varrho}{\bar{D}}$ chelation in vivo, for which we have given $\stackrel{Ð}{\oplus}$ evidence; similar findings have also been made with desferrioxamine (Fielding, 1965; Hallberg ${ }_{0}^{\circ}$ and Hedenberg, 1965). Evidence that injected $\mathbb{D}$ ${ }^{59} \mathrm{Fe}-\mathrm{DTPA}$ may be used as a marker for the $\frac{O}{\mathbb{D}}$ excretion of chelated tissue iron is indicated by $\cong$ the proportionately identical variation in the excretion of each with changing body iron 8 content.

The iron excretion produced by DTPA in our 흘. control subjects and patients with untreated 
haemochromatosis agrees closely with the results of Powell (1965). Slightly lower values were obtained in healthy volunteers by Walsh et al (1963), possibly reflecting certain differences in their methods. The significant sex difference in iron excretion in our controls accords with the demonstration by Weinfeld (1964) that women of all age groups have significantly lower storage iron concentrations in liver and bone marrow than men. The inability of Walsh et al (1963) and Powell (1965) to find a significant difference in iron excretion between their male and female controls probably reflects their use of a fixed dose of $1 \mathrm{~g}$ DTPA for all adult subjects. The need to relate dose to some parameter of body size is indicated by the linear relationship between iron excretion and dose in both the normal (Barry and Cartei, unpublished observations) and the iron-loaded subject (Figueroa, 1964). Our regimen of $16.7 \mathrm{mg} / \mathrm{kg}$ body weight approximates to a total dose of $1,000 \mathrm{mg}$ in an adult of average size.

Hitherto only Powell and Thomas (1967) have attempted to equate DTPA-induced iron excretion with body storage iron on an exact basis. The simple linear correlation that they found in a rather small number of observations is not confirmed by the highly significant semi-logarithmic relationship obtained here. However, this form of the dependency did not apply for iron loads of less than $2 \mathrm{~g}$; although the reason for this is not clear it is possible that at low iron loads the size of the stores is no longer a factor for the stability of the iron-chelate complex.

There was a highly significant linear correlation between DTPA-chelatable iron and body storage iron. This was examined in two ways, the first (Fig. 6) reflecting the interaction between the chelating agent and all tissue iron components, and the second its interaction with storage iron exclusively; the almost exact identity of the two regression lines, and the close approximation of both to the origin, implies that the action of DTPA is specifically related to the storage iron compartment. Analysis of data corresponding to that in Fig. 6 obtained in the same patients with desferrioxamine gave a regression line that deviated significantly from the origin, indicating that desferrioxamine derived some iron from a tissue source unrelated to the stores (Barry et al, 1969). This difference between the two compounds may be related to their respective tissue distributions, experimental evidence suggesting that the desferrioxamine-space is wider than that of DTPA and approximates to total body water (Peters, Keberle, Schmid, and Brunner, 1966).

The SE of the mean estimate for storage iron on DTPA-chelatable iron $(0.25 \mathrm{~g})$ was identical with the corresponding value based on the logarithm of the simple urinary iron excretion. In retrospect it is not surprising that the two modalities proved equally precise in the present group of patients, as the variable by which they are related $\left({ }^{59} \mathrm{Fe}-\mathrm{DTPA}\right.$ excretion) was also highly correlated with the size of the stores. However, these interrelationships may not always so closely apply. The frequently low excretion of ${ }^{59} \mathrm{Fe}-\mathrm{DTPA}$ in oedematous states and with renal impairment implies that chelate stability may be subject to influences other than storage iron load, and we have therefore regarded chelatable iron as the more reliable index of the size of the stores. Moreover, the relationship between DTPA-chelatable iron and storage iron did not deviate from linearity at low iron loads and was better defined in this part of the range than the relationship between simple iron excretion and storage iron.

Using this technique it has been possible to predict with considerable accuracy the iron load in patients with haemochromatosis and in their mildly affected relatives. Provided that blood is removed at a rate of not less than $500 \mathrm{ml} /$ week the total number of venesections required can be forecast at the outset of treatment. Due to the role of alimentary iron absorption, which is enhanced during treatment (Williams, Manenti, Williams, and Pitcher, 1966), a more gradual rate of blood removal results in a less efficient negative iron balance so that the predicted values will then underestimate both the amount of iron subsequently removed and the number of venesections required.

The chelatable iron values in the controls indicated a mean ( \pm SEM) storage iron of $392 \pm$ $41 \mathrm{mg}$ for the 16 males and $243 \pm 32 \mathrm{mg}$ for the nine females, with a maximum individual content of $693 \mathrm{mg}$. These findings agree well with previous estimates of normal storage iron based on venesection studies in healthy volunteers. Thus Haskins, Stevens, Finch, and Finch (1952) found a range of 93 to $844 \mathrm{mg}$ in four haematologically normal volunteers, including two former blood donors. Pritchard and Mason (1964) found the iron stores to be $580-940 \mathrm{mg}$ in three subjects and Hynes (1949) calculated a value of $600 \mathrm{mg}$ in one subject. Balcerzak et al (1968) found a mean storage iron of $687 \mathrm{mg}$ in 11 subjects but made no correction for absorption during the study. The only study involving women was that of Pritchard and Mason (1964) who found a mean of $254 \mathrm{mg}$ for 10 healthy subjects-very similar to the value found here. Comparable results were also obtained from a long-term isotope 'dilution study of body iron exchange by Finch (1959) who calculated an average miscible iron store of $600 \mathrm{mg}$ in men and about $380 \mathrm{mg}$ in pre- and postmenopausal women respectively.

We thank Dr P. J. Scheuer for reporting the liver biopsies. DTPA was generously supplied by Dr J. G. Domenet of Geigy Pharmaceuticals. M.B. was in receipt of a Saltwell scholarship from the Royal College of Physicians. The material reported in this paper was included in a 
thesis submitted by M.B. for the degree of MD at the University of Cambridge.

\section{References}

Balcerzak, S. P., Westerman, M. P., Heinle, E. W., and Taylor, F. H. (1968). Measurement of iron stores using deferoxamine. Ann. intern. Med., 68, 518-525.

Barry, M. (1968). Determination of chelated iron in the urine. J. clin. Path., 21, 166-168.

Barry, M., Cartei, G., and Sherlock, S. (1969). Differential ferrioxamine test in haemochromatosis and liver diseases. Gut, 10,697-704.

Cleton, F. (1964). Discussion. In Iron Metabolism. An International CIBA Symposium, edited by F. Gross, p. 522. Springer, Berli .

Cleton, F., Turnbull, A., and Finch, C. A. (1963). Synthetic chelating agents in iron metabolism. J. clin. Invest., 42, 327-337.

Fielding, J. (1965). Differential ferrioxamine test for measuring chelatable body iron. J. clin. Path., 18, 88-97.

Fielding, J. (1967). Desferrioxamine chelatable body iron. J. clin. Path., 20, 668-670.

Figueroa, W. G. (1964). Discussion. In Iron Metabolism. An International CIBA Symposium, edited by F. Gross, pp. 523-524. Springer, Berlin.

Figueroa, W. G., and Thompson, J. H. (1968). Biliary iron excretion in normal and iron-loaded rats after desferrioxamine and Ca DTPA. Amer. J. Physiol., 215, 807-810.

Finch, C. A. (1959). Body iron exchange in man. J. clin. Invest., 38, 392-396.

Foreman, H. (1960). The pharmacology of some useful chelating agents. In Metal Binding in Medicine, edited by $\mathrm{M}$. J. Seven and L. A. Johnson, pp. 82-94. Lippincott, Philadelphia.

Foreman, H., and Trujillo, T. T. (1954). The metabolism of ${ }^{14} \mathrm{C}$-labelled ethylenediaminetetra-acetic acid in human beings. J. Lab. clin. Med., 43, 566-571.

Foreman, H., Vier, M., and Magee, M. (1953). The metabolism of ${ }^{14} \mathrm{C}$-labelled ethylenediaminetetra-acetic acid in the rat. J. biol. Chem., 203, 1045-1053.

Hallberg, L., and Hedenberg, L. (1965). The effect of desferrioxamine on iron metabolism in man. Scand. J. Haemat., 2, 67-79.

Hallberg, L., Hedenberg, L., and Weinfeld, A. (1966). Liver iron and desferrioxamine-induced urinary iron excretion. Scand. J. Haemat., 3, 85-98.

Harker, L. A., Funk, D. D., and Finch, C. A. (1968). Evaluation of storage iron by chelates. Amer. J. Med., 45, 105-115.
Haskins, D., Stevens, A. R., Finch, S. C., and Finch, C. A. (1952). Iron metabolism. Iron stores in man as measured by phlebotomy. J. clin. Invest., 31, 543-547.

Hynes, M. (1949). The iron reserve of a normal man. J. clin. Path., 2,99-102.

Lundvall, O., and Weinfeld, A. (1969). Iron stores in alcohol abusers. II. As measured with the desferrioxamine test. Acta med. scand., 185, 271-277.

Meyer-Brunot, H. G., and Keberle, H. (1967). The metabolism of desferrioxamine $B$ and ferrioxamine B. Biochem. Pharmacol., 16, 527-535.

Peters, G., Keberle, H., Schmid, K., and Brunner, H. (1966). Distribution and renal excretion of desferrioxamine and ferrioxamine in the dog and in the rat. Biochem. Pharmacol., 15, 93-109.

Powell, L. W. (1965). Iron storage in relatives of patients with haemochromatosis and in relatives of patients with alcoholic cirrhosis and haemosiderosis. Quart.J. Med.,34, 427-442

Powell, L. W., and Thomas, M. J. (1967). Use of diethylenetriamine penta-acetic acid (DTPA) in the clinical assessment of total body iron stores. J.clin. Path., 20, 896-904.

Pritchard, J. A., and Mason, R. A. (1964). Iron stores of normal adults and replenishment with oral iron therapy. J. Amer. med. Ass., 190, 897-901.

Scheuer, P. J., Williams, R., and Muir, A. R. (1962). Hepatic pathology in relatives of patients with haemocromatosis. J. Path. Bact., 84, 53-64.

Schubert, J. (1964). Discussion. In Iron Metabolism. An International CIBA Symposium, edited by F. Gross, p. 522. Springer, Berlin.

Smith, P. M., Lestas, A. N., Miller, J. P. G., Dymock, I. W., Pitcher, C. S., and Williams, R. (1969). The differential ferrioxamine test in the management of idiopathic haemochromatosis. Lancet, 2, 402-405.

Smith, R. S. (1964). Chelating agents in the diagnosis and treatment of iron overload in thalassaemia. Ann. N.Y. Acad. Sci., 119, 776-788.

Stevens, E., Rosoff, B., Weiner, M., and Spencer, H. (1962), Metabolism of the chelating agent diethylenetriamine penta-acetic acid $\left({ }^{14} \mathrm{C}\right.$-DTPA) in man. Proc. Soc. exp. Biol. N.Y., 111, 235-238.

Walsh, R. J., Perkins, K. W., Blackburn, C. R. B., Sanford, R. and Cantrill, S. (1963). The use of DTPA in the diagnosis and management of idiopathic haemochromatosis. Aust. Ann. Med., 12, 192-196.

Weinfeld, A. (1964). Storage iron in man. Acta med. scand., 177, Suppl. 427.

Williams, R., Manenti, F., Williams, H. S., and Pitcher, C. S (1966). Iron absorption in idiopathic haemochromatosis before, during, and after venesection therapy. Brit. med.J., 2, 78-81.

Young, D. S., and Hicks, J. M. (1965). Method for the automatic determination of serum iron. J. clin. Path., 18, 98-102. 